\title{
AN OSTEOMETRIC STUDY OF THE SKULL OF ADULT BEETAL GOAT
}

\author{
S. Din ${ }^{1}$, S. Masood ${ }^{1}$, H. Zaneb ${ }^{1}$, H. Rehman², S. Ashraf, I. Khan ${ }^{3}$, M. Shah ${ }^{4}$ and S. A. Hadi ${ }^{1}$ \\ ${ }^{1}$ Department of Anatomy and Histology, ${ }^{2}$ Department of Physiology, University of Veterinary and Animal Sciences, \\ Lahore, Pakistan; Abdul Wali Khan University, Mardan; Agricultural University Peshawer, Pakistan \\ Corresponding Author's email: saima.masood@uvas.edu.pk
}

\begin{abstract}
Beetal is a large-sized goat breed in Pakistan, produce an average from 1.5 to 3 liters of milk on daily basis and is known for several features, including heat tolerance, prolificacy, and multi-purpose utilization. In spite of such remarkable features, gross anatomical characteristics of these goats are still not explored. Therefore, this preliminary study was designed to measure clinically important landmarks in the skull of adult Beetal goat in both sex as an attempt to provide a baseline data. Skulls $(n=20)$ of Beetal goats (10 each of males and females) were used in the study. The skulls of both sexes were collected from apparently clinically healthy goats after slaughtering at an abattoir and treated according to the hot water maceration procedures. Biometric parameters were measured with the help of a digital vernier calliper. Descriptive statistics of the measured skull parameters did not show statistically significant differences between male and female adult Beetal goat. However, the studied parameters demonstrated variations from previously reported data in other breeds of goat and sheep. The measured anatomical standards are of clinical significance and will aid in regional nerve blocks and archaeological studies.
\end{abstract}

Key words: Beetal Goat, Skull, Morphometry, Sexual dimorphism

https://doi.org/10.36899/JAPS.2020.4.0097

Published online March 25, 2020

\section{INTRODUCTION}

Domestic goats (C. hircus) as one of the primogenital domesticated livestock, that are extensively raised all over the world due to their significance in culture, agriculture, and economy since the Neolithic agricultural insurgency (Naderi et al., 2008). Beetal is a goat breed in Pakistan, maybe horned or polled and is reflected as a large-sized breed. Beetal goats are known for a number of features, including heat tolerance, prolificacy, and multi-purpose utilization. Beetal goats are found almost everywhere in the province of Punjab (Pakistan), and are approximately $4 \%$ of the total goat population which is nearly 59 million (GOP, 2009). Beetal goats produce on an average from 1.5 to 3 liters of milk on a daily basis (GOP, 2009). Beetal goat is proven to be superior among other goat breeds for higher productive performance in both milk and meat production (Wajid et al., 2013). Testicular biometry and growth curve of Beetal goats were described by Waheed et al., (2011). The characteristic features of the Interferon alpha (IFN- $\alpha$ ) gene, in the Beetal goat breed of Punjab, Pakistan was studied, this gene plays an essential role in innate immune reaction with biological and antiviral activity (Yasmeen et al., 2017). However, the basic and applied gross and histological features of this goat are still not studied.

Animal gross morphological features show the significant dissimilarity with respect to age, breed, sex, environmental factors and nutritional condition among others. The measurements of these factors are important symbols for comparison. A lot of biometrical studies on skeleton have been carried out inline to obtain a more objective genetic assessment (Kunzel et al., 2003; Brombin et al., 2009). These biometrical data of skeleton obtained for genetic assessment are significant in anthropology (Bokonyi, 1974), regional anesthesiology (Olopade and Onwuka, 2005), taxonomy, (Habel, 1982) and comparative gross anatomical and histological descriptions between and within breeds (Olopade et al., 2006). The applied morphology of the head region is essential because of the presence of vital organs like brain, tongue, eyes as well as ears, teeth, nose, lips, horn, and skull (Dyce et al., 2002). The cranial nerves of medical significance in the regional anesthesia arise from the brain and exit through different foramina in the skull bones (Hall et al., 2000). As, gross anatomy of the head has been well described previously in horse, ox and dog (Getty, 1975; Dyce et al., 2002 and Onar et al., 2001), however, there is no inclusive data on the regional applied morphology of the skull of Beetal goats. Therefore, the objective of this study was to measure some clinically important landmarks in the skull of male and female adult Beetal goat to provide reference data to veterinary practitioners, archaeologist, and researchers.

\section{MATERIALS AND METHODS}

Animals and Sample Collection: A total of 20 skulls along with the mandibles of adult male and female Beetal 
goats were studied. Live animals apparently healthy and had no skeletal deformities were observed in an abattoir during the collection of skulls. The goat's heads were severed at the occipitoatlantal joint after slaughtering and treated according to the hot water maceration procedures (Tasbas and Tecirlioglu, 1996) and Allouch and Alshick (2008) and the University of Arizona cooperative and extension paper on cleaning and skull preparation (1999). The heads after collection in abattoir were kept in a solution of polycarboxylate and detergent and boiled above $80^{\circ} \mathrm{C}$ for 30 minutes than the heated heads were put in water and detached muscles with the help of a sharp scalpel. For further cleaning of the remaining muscles and ligament, the skulls were kept again in $1 \%$ sodium hypochlorite solution for 24 hours. The final stage of processing involved cleaning of the skulls in tap water and then left the skull to dry completely. After collection of all the required bones, these were kept in isolated boxes. The gross osteometric studies were carried out at the University of Veterinary and Animal Sciences, Lahore, Pakistan. Osteometric measurements were taken using a digital vernier calliper according to craniometrical points (Von Den Driesch, 1976; Zedda et al., 2006 and Chrószcz, 2007).

Skull Parameters (Fig. 1): Skull length, Skull width, Skull/Cephalic index (SI = Skull length / Skull width $\mathrm{x}$ 100) Supraorbital foramina distance, Distance between orbital rim to supraorbital foramina, Infraorbital foramina distance to orbit, Diameter of Infraorbital foramina, Distance from the process of the alveolar socket of canine tooth to the infraorbital canal, Infra-orbital canal to the root of alveolar tooth and between infraorbital foramina to orbital rim.

Orbital parameters (Fig. 2): Orbit height (LO), Orbit length (WO), Orbital depth (DO), Orbital index (OI = Orbital length / Orbital breadth x 100), Interorbital interval at different points: i) at rostral extent. (IORE) ii) at central extent (IOCE) iii) at the caudal extent (IOCDE).

Nasal Parameters: Length of the nasal bone, Width across nasal bone:

Foramen Magnum parameters (Fig. 3): The height of the Foramen Magnum (FMH), Width of the Foramen Magnum (FMW), Thickness of the Occipital Condyle (OCT), Width of the Intercondylar bones (ICW), Width of the Interparacondylar bones (IPCW), Length of the Paracondylar Process (PCPL).

Mandibular parameters (Fig. 4 and 5): Lateral alveolar root to the mental foramen (a), Mental foramen to the caudal mandibular border (b), Mandibular length (c), Mandibular foramen to the base of mandible (d), Caudal border of mandible to below mandibular foramen (e), Condyloid fossa to the height of the mandible (f),
Maximum mandibular height (g) and Condyloid fossa to the base of the mandible (h)

The measurements were repeated three times by two independent observers, and the mean values were recorded. The bones were described using the terminology given in Nomina Anatomica Veterinaria 2012, 5th Edn.

Statistical Design: The above-mentioned parameters of the skull and mandible were calculated and expressed as the mean \pm standard deviation (SD) and means of male and female beetal goat were compared with a Student ttest. Analysis of data was conducted using SPSS version 20.0 (SPSS, Inc., Chicago, IL) and differences were considered significant at $\mathrm{P}<0.05$.

\section{RESULTS AND DISCUSSION}

Various skull and mandibular parameters of both adult male and female Beetal goat calculated are tabulated in Tables 1-4. Descriptive statistics of the measured skull parameters did not show statistically significant differences $(p>0.05)$ between adult male and female Beetal goat which is in accordance with the findings in most of the craniometric dimensions in the Pyrenean chamois (Garcia-Gonzalez and Barandalla, 2002) and the goats found in the middle regions of Nigeria (Samuel et al., 2013), in which no marked sexual dimorphism was observed in most of the skull indices measured. Osteometric dimensions are used for the identification of species and recognition of intra-species variations (Yalçin and Kaya, 2009; Karimi et al., 2011 and Sheremetyeva and Sheremetyev, 2008). The measured anatomical standards are of clinical significance and will help in local nerve blocks of mandibular, mental and infraorbital nerves and hence it is ascertained in the current study to adopt the same approach to access cranial nerves in both sexes of Beetal goat.

The current analysis shows that the skull length is nearly similar to the value described in the Mehraban sheep (Karimi et al., 2011), in Iranian Native sheep (Monfared, 2013) and is higher than those reported in West African Dwarf Goat (Olopade and Onwuka, 2005), in the Gwembe Valley Dwarf goat (Kataba, 2014) and Markhoz goat (Goodarzi and Hoseini, 2014). However, it is lower than the values reported in the Red Sokoto goat (Olopade and Onwuka, 2007), Kagani goat (Sarma, 2006) and Barbados Black Belly sheep (Mohamed et al., 2016). The skull width in this study is higher than the goats found in the middle regions of Nigeria (Samuel et al., 2013) and Markhoz goat of Western Iran (Goodarzi and Hoseini, 2014). In this study and from the previous reports on other goat breeds, it may be concluded that a specific goat breed cannot be used as a reference in other 
goats breed in any surgical procedures of the head or for archaeological study.

Cephalic/ skull index is an essential parameter in forensic medicine, anthropology and gender determinations (Lakshmi et al., 2015). The skull indices in male and female Beetal goat recorded in this study is $57.32 \pm 0.10$ and $57.72 \pm 0.14$, respectively. However, lower skull indices of 41.95 has been reported in Kagani goat (Sarma, 2006), (47.77 \pm 1.96$)$ in Markhoz goat (Goodarzi and Hoseini, 2014) and 53.57 in Mehraban sheep (Karimi et al., 2011). The average distance between the supraorbital foramina is lower than the value mentioned (Monfared, 2013) in the Iranian Native sheep and Barbados Black Belly sheep (Mohamed et al., 2016).

Detailed information about the location of the foramen and the infraorbital nerve can offer a harmless clinical procedure, such as a surgical procedure, the practice of intra and extra oral anesthesia (Mozsary and Middleton, 1983; Lawrence and Poole, 1992 and Zide and Swift, 1998). In the present study, the distance from the process of the alveolar socket of a canine tooth to the infraorbital foramen is more than in Markhoz goat (Goodarzi and Hoseini, 2013). However, it is lower than the Iranian Native goat (Monfared et al., 2013) and the Gwembe Valley Dwarf goat (Kataba, 2014). These conclusions are of high clinical implication concerning to the infra-orbital nerve block. The injection of a local anesthetic agent through the infra-orbital foramen causes the analgesia of the incisor, canine and the first two premolar teeth (Hall et al., 2000). These data will corroborate to the regional anesthesia of the areas innervated by the infra-orbital nerve in the Beetal goats.

The overall mean distance between orbital rim to supraorbital foramina in our study is more than the values reported for the same parameter by Samuel et al. (2013) in goats found in the middle regions of Nigeria, which are $1.84 \pm 0.76 \mathrm{~cm}$ in the West African Dwarf (WAD), $1.96 \pm 0.02 \mathrm{~cm}$ in the Sahel breed (SH) and $1.60 \pm 0.34 \mathrm{~cm}$ for the Red Sokoto breed (RS) for a similar landmark. The measurements of cranial indices are important in regional anesthesia of the head for rostral dental procedures of the upper jaw and the desensitization of the cornual process for dehorning (Hall et al., 2000).

The measurement of foramen magnum diameter is used in species comparison, in addition to this, many researchers highlighted the usefulness of foramen magnum diameter in the differentiation of sex within the species (Göçmez et al., 2014; İlgüy, 2014; Simoens, 1994 and Uthmanet et al., 2012) which is of high significance in forensic investigations. The foramen magnum height and width in this study is higher from the RS breed (Kwari, 2001) and SH breed goats (Shawulu et al., 2008) and WAD breed (Olopade, 2006), which are reported to be $1.79 \mathrm{~cm}, 1.85 \mathrm{~cm}$ and $1.68 \mathrm{~cm}$, respectively. On the contrary, Samuel et al., (2013) reported higher values $(2.26 \mathrm{~cm}$ and $2.90 \mathrm{~cm})$ for the same indices in goats found in the middle regions of Nigeria. The foramen index in male and female Beetal goat recorded in this study are $84.62 \pm 2.05$ and $85.16 \pm 0.04$, respectively. However, higher foramen index $(89.32 \pm 14.1)$ reported in Markhoz goat (Goodarzi and Hoseini, 2014) and 102.5 in West African Dwarf goat (Olopade and Onwuka, 2005). From this study, it may be proposed a divergence in morphology, like other measurements in the foramen magnum height and width, shows variation from other breeds.

Mean values of the mandibular parameters mental foramen to the caudal mandibular border (b), mandibular foramen to base of mandible (d), caudal border of mandible to below mandibular foramen (e), condyloid fossa to the height of the mandible (f), maximum mandibular height and condyloid fossa to the base of the mandible $(h)$ are not significantly $(\mathrm{p}<0.5)$ different between adult male and female Beetal goat. However, "mean values for lateral alveolar root to the mental foramen (a)" and "mandibular length (c)" are significantly higher for male than a female adult Beetal goat (Table 4). The mandibular length in Beetal goat is higher than the values reported in Markhoz goat (Goodarzi and Hoseini, 2013), and in Iranian Native goat (Monfared et al., 2013). The mean value obtained in this study for mandibular foramen to the base of the mandible is nearly same to the value $(3.43 \pm 0.25 \mathrm{~cm})$ reported in Markhoz goat (Goodarzi and Hoseini, 2013), and higher than WAD and Iranian native goat, which are reported to be $2.58 \pm 0.34 \mathrm{~cm}$ (Olopade, 2005) and $2.88 \pm 0.93 \mathrm{~cm}$ (Monfared, 2013), respectively. The distances between the condyloid fossa to the height of the mandible and the value for condyloid fossa to the base of the mandible are higher in Beetal goat than those reported in Markhoz goats (Goodarzi and Hoseini, 2013, WAD goat (Olopade, 2005) and Iranian native goat (Monfared, 2013).

In conclusion, according to our findings, the study demonstrated a lack of sexual dimorphism in most of the osteometric parameters and this could be of importance in clinical approach, paleontological studies, comparisons of the results of the studied parameters of this study with earlier studies resulted in large variations of the anatomical landmarks within different breed of goats and also with sheep. There is no previous literature on these parameters in Beetal goat, or in any other goat breeds in Pakistan, which may be used as a reference for clinical procedures on the head region. We, therefore, consider that the data presented above will form an important baseline for further research work and will be helpful to clinicians for comparative anatomical and developmental studies between different breeds of goat. 
Table 1. Measurements (Mean \pm SD) of skull parameters of adult Beetal goat based on sex in $\mathrm{cm}$.

\begin{tabular}{|c|c|c|c|}
\hline & Female & Male & P-value \\
\hline Skull length & $19.73 \pm 0.11$ & $19.99 \pm 0.25$ & 0.17 \\
\hline Skull width & $11.37 \pm 0.08$ & $11.39 \pm 0.07$ & 0.68 \\
\hline Skull/Cephalic index & $57.32 \pm 0.10$ & $57.72 \pm 0.14$ & 0.34 \\
\hline Supraorbital foramina distance & $4.59 \pm 0.08$ & $5.28 \pm 0.09$ & 0.37 \\
\hline Distance between orbital rim to supraorbital foramina & $3.19 \pm 0.08$ & $3.27 \pm 0.08$ & 0.83 \\
\hline Infraorbital foramina distance to orbit & $6.01 \pm 0.10$ & $6.07 \pm 0.09$ & 0.95 \\
\hline Diameter of Infraorbital foramina & $0.42 \pm 0.08$ & $0.51 \pm 0.09$ & 0.98 \\
\hline Distance from process of alveolar socket of canine tooth to the infraorbital canal & $6.94 \pm 0.11$ & $7.01 \pm 0.12$ & 0.53 \\
\hline Infra-orbital canal to the root of alveolar tooth & $1.95 \pm 0.06$ & $1.99 \pm 0.09$ & 0.61 \\
\hline between Infraorbital foramina to rim & $3.86 \pm 0.07$ & $3.89 \pm 0.06$ & 0.94 \\
\hline
\end{tabular}

Table 2. Measurements $($ Mean \pm SD) of Orbital and Foramen Magnum parameters of the skull of male and female adult Beetal goat in $\mathbf{c m}$.

\begin{tabular}{cccccccc}
\hline & Male & Female & P-value & & Male & Female & P-value \\
\hline Lo & $4.25 \pm 0.06$ & $3.40 \pm 0.06$ & 0.54 & FMH & $2.39 \pm 0.07$ & $2.35 \pm 0.06$ & 0.76 \\
Wo & $3.40 \pm 0.06$ & $4.25 \pm 0.06$ & 0.94 & FMW & $2.02 \pm 0.03$ & $2.00 \pm 0.04$ & 0.43 \\
OI & $80.16 \pm 0.08$ & $80.00 \pm 0.34$ & 0.17 & FMI & $84.62 \pm 0.05$ & $85.16 \pm 0.04$ & 0.17 \\
Do & $3.63 \pm 0.05$ & $3.60 \pm 0.06$ & 0.50 & OCT & $1.54 \pm 0.06$ & $1.51 \pm 0.04$ & 0.49 \\
IORE & $8.79 \pm 0.06$ & $8.77 \pm 0.07$ & 0.68 & ICW & $4.93 \pm 0.05$ & $4.90 \pm 0.03$ & 0.59 \\
IOCE & $10.64 \pm 0.06$ & $10.62 \pm 0.04$ & 0.54 & IPCW & $8.04 \pm 0.04$ & $8.01 \pm 0.05$ & 0.96 \\
IOCDE & $11.90 \pm 0.07$ & $11.89 \pm 0.05$ & $\mathbf{0 . 3 2}$ & PCPL & $2.75 \pm 0.07$ & $2.73 \pm 0.05$ & 0.34 \\
\hline
\end{tabular}

Differences were considered significant at $\mathrm{P}<0.05$.

Orbit height (Lo), Orbit length (WO), Orbital index (OI) Orbital depth (Do), Interorbital interval at different points: i) at rostral extent. (IORE) ii) at central extent (IOCE) iii) at caudal extent (IOCDE). Height of the Foramen Magnum (FMH), Foramen index (FMI), Width of the Foramen Magnum (FMW), Thickness of the Occipital Condyle (OCT), Width of the Intercondylar bones (ICW), Width of the Interparacondylar bones (IPCW), Length of the Paracondylar Process (PCPL).

Table 3. Measurements (Mean \pm SD) of the facial bones of the skull of male and female adult Beetal goat in $\mathrm{cm}$.

\begin{tabular}{ccccc}
\hline & & MALE & FEMALE & $1.29 \pm 0.05$ \\
Maxilla & Lma & $1.15 \pm 0.04$ & $1.53 \pm 0.04$ & 0.16 \\
Premaxilla & Wm & $1.95 \pm 0.07$ & $7.15 \pm 0.04$ & 0.03 \\
& Lpm & $7.25 \pm 0.05$ & $5.95 \pm 0.07$ & 0.55 \\
Lacrimal & Wpm & $5.99 \pm 0.06$ & $1.29 \pm 0.05$ & 0.58 \\
& Lla & $1.29 \pm 0.05$ & $1.53 \pm 0.04$ & 0.49 \\
Nasal & Wla & $1.53 \pm 0.04$ & $8.72 \pm 0.50$ & 0.48 \\
& Lna & $8.72 \pm 0.50$ & $1.60 \pm 0.06$ & 0.46 \\
Palatine & Wna & $1.60 \pm 0.06$ & $13.29 \pm 0.05$ & 0.90 \\
& Lpa & $13.29 \pm 0.05$ & $2.87 \pm 0.06$ & 0.71 \\
\hline
\end{tabular}

Maxilla length (Lma), Maxilla width (Wma), Premaxilla length (Lpm), Premaxilla width (Wpm), Lacrimal length (Lla), Lacrimal width (Wla), Nasal length (Lna), Nasal width (Wna), Palatine length (Lpa), Palatine width (Wpa).

Table 4. Measurements (Mean \pm SD) of the mandible of adult Beetal goat in $\mathrm{cm}$.

\begin{tabular}{lccc}
\hline & Male & Female & P-value \\
\hline A & $2.36 \pm 0.11$ & $2.26 \pm 0.04$ & 0.00 \\
B & $15.17 \pm 0.10$ & $14.95 \pm 0.70$ & 0.08 \\
C & $18.79 \pm 0.05$ & $18.71 \pm 0.13$ & 0.03 \\
D & $3.60 \pm 0.05$ & $3.59 \pm 0.05$ & 0.55 \\
E & $1.90 \pm 0.04$ & $1.89 \pm 0.05$ & 0.35 \\
F & $6.58 \pm 0.04$ & $6.57 \pm 0.05$ & 0.23 \\
G & $10.38 \pm 0.04$ & $10.35 \pm 0.06$ & 0.20 \\
H & $4.01 \pm 0.12$ & $3.99 \pm 0.16$ & 0.60 \\
\hline
\end{tabular}

Lateral alveolar root to the mental foramen (a), mental foramen to the caudal mandibular border (b) Mandibular length (c) Man dibular foramen to base of mandible (d) Caudal border of mandible to below mandibular foramen (e) Condyloid fossa to the height of the mandible (f) Maximum mandibular height (g) Condyloid fossa to the base of the mandible (h). 
Table 5. The measurements (Mean \pm SD) of the mandible of Beetal goat compared to Gwembe valley, WAD, Markoz and Black Bengal goat.

\begin{tabular}{|c|c|c|c|c|c|c|}
\hline & $\begin{array}{c}\text { Male Beetal } \\
\text { goat }\end{array}$ & $\begin{array}{c}\text { Female Beetal } \\
\text { goat }\end{array}$ & $\begin{array}{c}\text { Gwembe valley } \\
\text { goat(Kataba } \text { et } \\
\text { al., 2014) }\end{array}$ & $\begin{array}{c}\text { WAD goat } \\
\text { (Olopade and } \\
\text { Onwuka, 2005) }\end{array}$ & $\begin{array}{l}\text { Markhoz goat } \\
\text { (Goodarzi and } \\
\text { Hosseini, 2013) }\end{array}$ & $\begin{array}{c}\text { Black Bengal } \\
\text { goat (Uddin et } \\
\text { al., 2009). }\end{array}$ \\
\hline $\mathbf{a}$ & $2.36 \pm 0.11$ & $2.26 \pm 0.04$ & $1.58 \pm 0.19$ & $1.56 \pm 0.22$ & $1.58 \pm 0.11$ & $2.11 \pm 0.17$ \\
\hline b & $15.17 \pm 0.10$ & $14.95 \pm 0.70$ & $9.26 \pm 0.49$ & $9.96 \pm 1.67$ & $11.42 \pm 0.42$ & $11.69 \pm 0.4$ \\
\hline c & $18.79 \pm 0.05$ & $18.71 \pm 0.13$ & $11.24 \pm 0.52$ & $12.0 \pm 1.89$ & $13.37 \pm 0.67$ & $14.21 \pm 0.98$ \\
\hline d & $3.60 \pm 0.05$ & $3.59 \pm 0.05$ & $2.35 \pm 0.26$ & $2.58 \pm 0.34$ & $3.43 \pm 0.25$ & $3.64 \pm 0.23$ \\
\hline e & $1.90 \pm 0.04$ & $1.89 \pm 0.05$ & $1.10 \pm 0.07$ & & $1.19 \pm 0.17$ & $1.47 \pm 0.25$ \\
\hline f & $6.58 \pm 0.04$ & $6.57 \pm 0.05$ & $1.43 \pm 0.22$ & $2.2 \overline{1 \pm 0.37}$ & $2.45 \pm 0.15$ & $2.36 \pm 0.23$ \\
\hline g & $10.38 \pm 0.04$ & $10.35 \pm 0.06$ & $6.64 \pm 0.44$ & $6.9 \pm 1.09$ & $8.94 \pm 0.43$ & $8.83 \pm 0.57$ \\
\hline h & $4.01 \pm 0.12$ & $3.99 \pm 0.16$ & $4.07 \pm 0.37$ & $2.68 \pm 0.45$ & $5.87 \pm 0.44$ & $6.38 \pm 0.51$ \\
\hline
\end{tabular}

Lateral alveolar root to the mental foramen (a), mental foramen to the caudal mandibular border (b) Mandibular length (c) Mandibular foramen to base of mandible (d) Caudal border of mandible to below mandibular foramen (e) Condyloid fossa to the height of the mandible (f) Maximum mandibular height (g) Condyloid fossa to the base of the mandible (h).

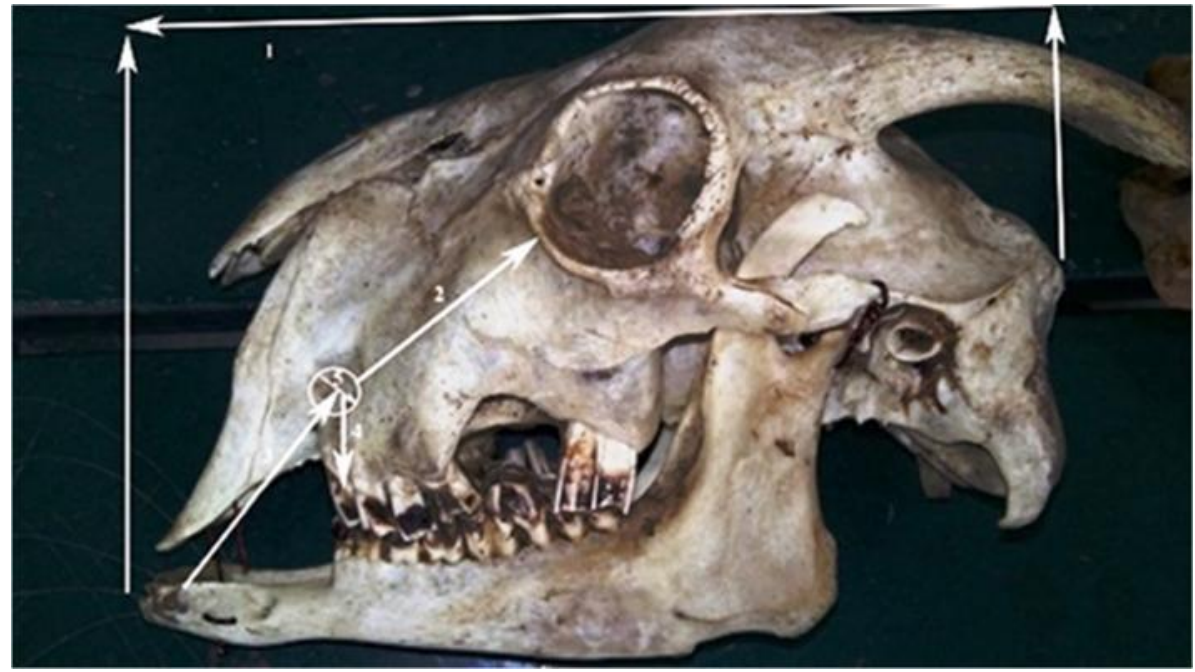

Fig 1. Skull of Beetal goat; lateral view. Skull length (1), Infraorbital foramina distance to orbit (2), Distance from process of alveolar socket of canine tooth to the infraorbital canal (3), Infraorbital canal to root of alveolar tooth (4), Diameter of Infraorbital foramina (5).

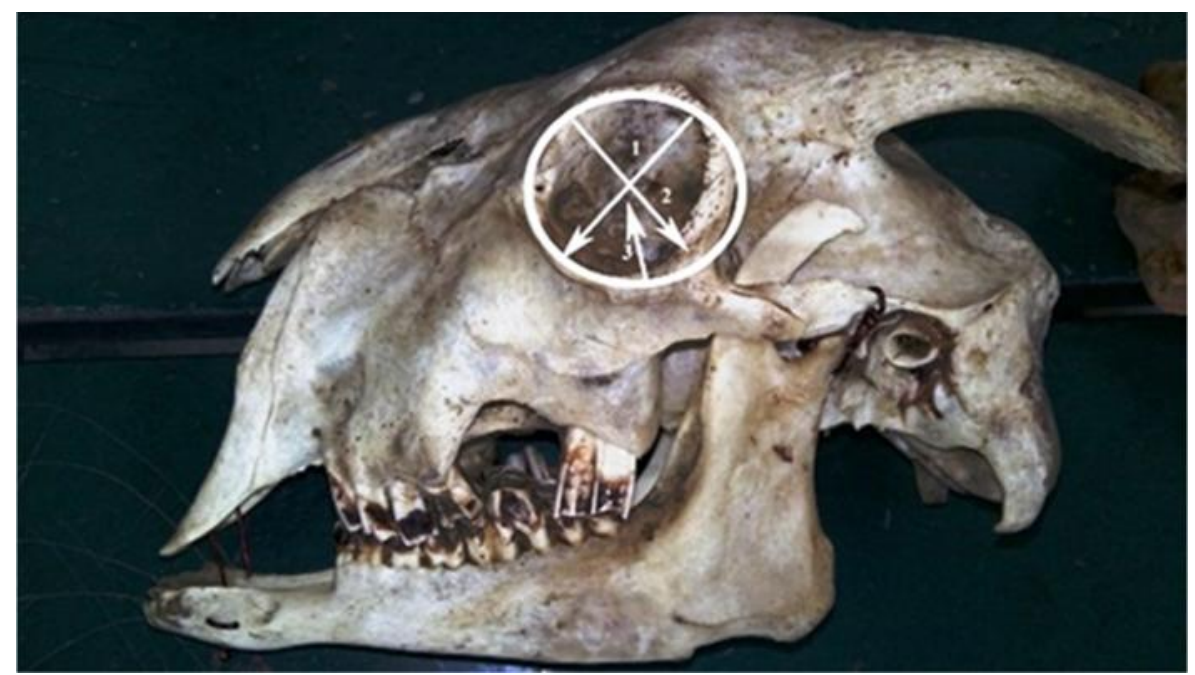

Fig. 2. Skull of Beetal goat; lateral view. Orbit height (1), Orbit length (2), Orbital depth (3). 


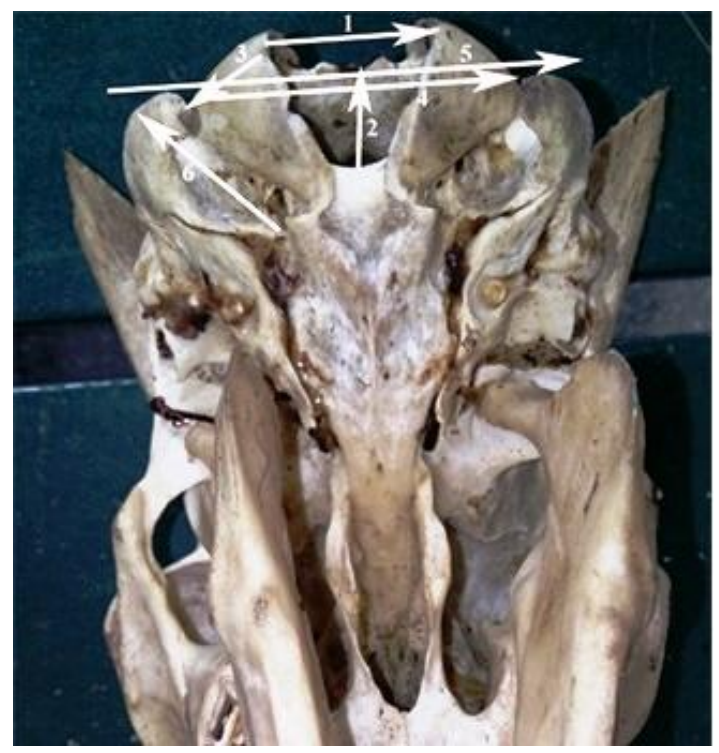

Fig 3. Width of the Foramen Magnum (1), Height of the Foramen Magnum (2), Thickness of the Occipital Condyle (3), Width of the Intercondylar bones (4), Width of the Interparacondylar bones (5), Length of the Paacondylar Process (6).

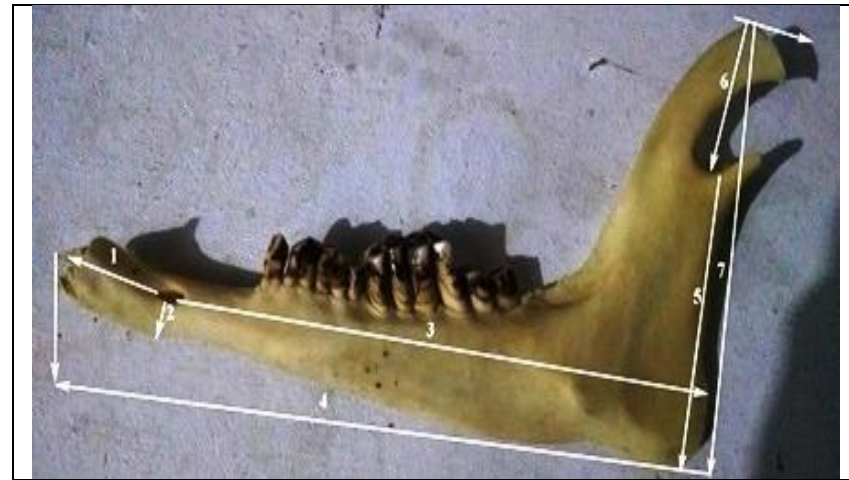

Fig 4. Mandilbe of adult Beetal goat showing Interval from lateral alveolar root to the mental foramen (1), Space from mental foramen to the caudal mandibular border (2), mental foramen (3), Mandibular length (4), Condyloid fossa to the base of the mandible (5), Condyloid fossa to the height of the mandible (6) Maximum mandibular height (7).

Conflict of interest: The authors have no conflict of interest

\section{REFERENCES}

Allouch, G. (2008). Textbook of Comparative anatomy, The Bones, Ligaments and Joints. Veterinary medicine collage, AL Baath University. 377 p

Bokonyi, S. (1974). History of domestic mammals in Central and Eastern Europe.

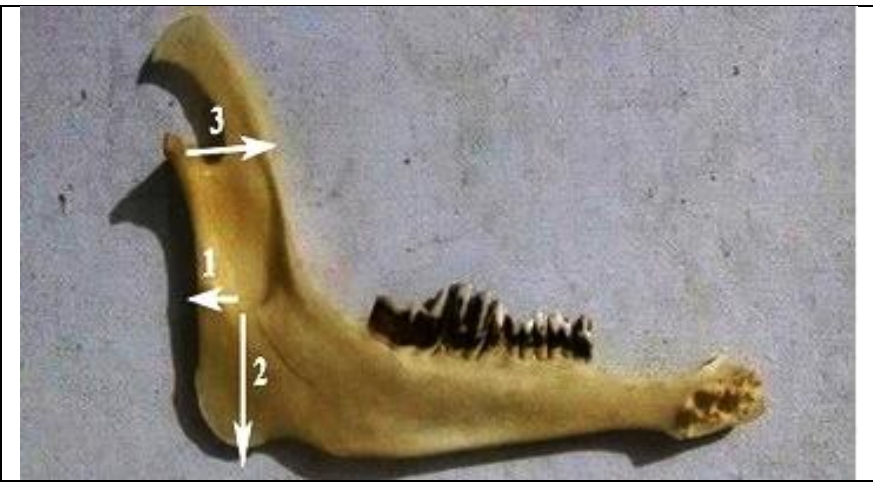

Fig 5. Mandilbe of adult Beetal goat showing Caudal border of mandible to below mandibular foramen(1) Mandibular foramen to the base of mandible (2). 
Driesch von den, A. (1976) A Guide to the measurement of animal bones from archeological sites. Peabody Museum Bulletin, Harvard University, Massachusetts.

Dyce, K.M., W.O. Sack, and C.J.G. Wensing (2002). Textbook of veterinary anatomy, 3rd edn. WB Saunders, Philadelphia.

Garcia-Gonzalez and Barandalla, (2002). Sexual dimorphism of phyrenean chamois based on skull morphometry. Pirinious. 157:25-37.

Getty, R. (1975). Equine and ruminant osteology. In Sisson and Grossman's. The anatomy of the domestic animals. R. Getty edn. I, $5^{\text {th }}$ edn. W.B. Saunders Company, Philadelphia. 273-317 p

Goodarzi, N. and T.J. Hoseini (2013). Morphometric Characteristics of the Maxillofacial and Mandibular Regions of Markhoz Goat Breed and its Clinical Value for Regional Anaesthesia in Western Iran. G.V. 11 (1): 107- 111.

GOP. (2009). Economic Survey of Pakistan 2008-09.

Habel, R.E. (1982). Ruminant introduction. In Sisson and Grossman, editors. The anatomy of the domestic animals. Philadelphia Saunders. 821-822 p

Hall, L.W., K.W. Clarke, and C.M. Trim (2000). Wright's veterinary anaesthesia and analgesia. $10^{\text {th }}$ edn. London, ELBS and Baillierre Tindall.

Karimi, I., V. Onar., G. Pazvant., M, Hadipour, and Y. Mazaher (2011). The Cranial Morphometric and Morphologic Characteristics of Mehraban Sheep in Western Iran. GV. 6(2): 111-117.

Kataba A, E.S. Mwaanga., H. Simukoko and C.P.M. Parés 2014. Clinical anatomy of the head Region of Gwembe Valley dwarf goat in Zambia. Inter J Vet Sci, 3(3): 142-146.

Kataba, A. (2014). Biometric morphologic characteristics of the skull of the Gwembe Valley Dwarf goat (Capra hircus). MVSC thesis, The university of Zambia, School of Veterinary Medicine, Biomedical Sciences Departments, Lusaka.,

Kunzel, W., S. Breit, and M. Oppel (2003). Morphometric investigation of breed specific features in feline skulls and considerations on their functional implications. Anat. Histol. Embryol. 32: 218-223.

Lakshmi, K.K., P.V.S.S. Vijaya., K.P. Kusuma, and M. Nagamani (2015). A study of cephalic index and facial index in Visakhapatnam, Andhra Pradesh, India. Int. J. Res. Med. Sci. 3: 656-8.

Lawrence, J.E. and M.D. Poole (1992). Mid-facial sensation following craniofacial surgery. British J. Plastic Surgery. 45(7): 519-522.

Mohamed, R., D.M. Marc, and N. Mootoo (2016). Clinical Anatomy of the skull of the Barbados Black Belly Sheep in Trinidad. Int. J. Curr. Res. Med. Sci. 2(8): 8-19
Monfared, A.L. (2013). Gross anatomical measurements of the head region of the Iranian native cattle Bos taurus and their clinical value for regional anesthesia. G.V. 10 (2): 219-222.

Mozsary, P.G. and R.A. Middleton (1983). Microsurgical reconstruction of the infraorbital nerves. J. Oral Maxillofac. Surg. 41(11): 697-700.

Nader, G. and S.H. Toraj (2014). Morphologic and Osteometric Analysis of the Skull of Markhoz Goat (Iranian Angora) Veterinary Medicine International Volume.

Naderi, S., H.R. Rezaei., F. Pompanon., M.G. Blum., R. Negrini, and H.R. Naghash (2008). The goat domestication process inferred from large-scale mitochondrial DNA analysis of wild and domestic individuals. Proc. Natl. Acad. Sci. U.S.A. 105(46): 17659-64.

Nomina Anatomica Veterinaria (2012). prepared by the International Committe on Veterinary Gross Anatomical Nomenclature (I.C.V.G.A.N.) and authorized by the General assembly of the World Association of Veterinary Anatomists (W.A.V.A.), konxville,T.N (USA). Published by the Editorial Committee, Hannover, Columbia, Ghent and Sapporo., 5th ed, 18-23 p

Olopade J.O. (2006). Morphometric analysis of the skull of three breeds of goats in Nigeria. PhD Thesis, Department of Veterinary Anatomy, faculty of Veterinary medicine, University of Ibadan Nigeria.

Olopade, J.O. and S. K. Onwuka (2005). "Morphometric study of the skull of the West African Dwarf Goat from SouthWest Nigeria," N.V.J. 26(2): $18-12$.

Olopade, J.O. and S.K. Onwuka (2007). Osteometric Studies of the Red Sokoto (Maradi) Goats (Capra hircus): Implication for Regional Anaesthesia of the Head. Int. J. Morphol. 25(2): 407-410.

Olopade, J.O., and S.K. Onwuka (2005). Some aspects of the clinical anatomy of the mandibular and maxillofacial regions of the west african dwarf goat in nigeria. Int. J. Morphol. 23 (1): 33-36.

Olopade, J.O., S.K. Onwuka., H.D. Kwari, and B.O. Oke (2006). Caudofrontal depression on the cornual end of the temporal line of the skull of goat breeds in Nigeria. Int. J. Morphol. 24:349- 350.

Onar, V. (1999). A morphometric study on the skull of in the German shepherd dog (Alsatian). Anat. Histol. Embryol. 28: 253-256.

Samuel, O.M., J.O. Olopade., M.R. Korzerzer, and S.K. Onwuka (2013). Craniometric evaluation of some cranial indices of clinical significance in goats (Capra Hircus) from the Middle-Belt Region of Nigeria - case for population 
surveillance and ecomigration, Eur $\mathrm{J}$ Wildlife Res. 2 (4): 89-97.

Sarma, K. (2006). Morphological and Craniometrical Studies on the Skull of Kagani Goat (Capra hircus) of the Jammu Region. Int. J. Morphol. 24: 449-455.

Shawulu, J.C., H. D. Kwari., J .O. Olopade, and S .K. Onwuka (2008). Trop. Vet. 26: 9-14.

Sullivan, M. L. and R.C. Park (1999). University of Arizona. The University of Arizona cooperative extension consultancy paper on cleaning and preserving animal skulls.

Tasbas, M and S. Tecirlioglu (1996). Meserasyon teknigi uzerinde arasirmalar. Ank. Uni. Vet. Fak Derg. X11, 4: 324-30.

Uddin, M.M., S.S. Uddin Ahmed., K.N. Islam and M.M. Islam (2009). Clinical anatomy of the head region of the Black Bengal goat in Bangladesh. Int. J. Morphol., 27(4):1269-1273.

Waheed, A., M. S. Khan., S. Ali, and M. Sarwar (2011). Estimation of growth curve parameters in Beetal goats. Arch. Tierz. 54: 287-296
Wajid, A., T. Hussain., M. Wasim., M.E. Babar., A.A. Anjum., S.A. Shah., K. Abbas., M.M. Manzoor, and N. Badshah (2013). The future prospective of genomic biotechnology in animal breeding: their potential for livestock production in Pakistan. The J. Anim. Plant Sci. 23(4): 944955.

Yasmeen A.1., T. Hussain., A. Ahmad., T. Yaqub., S. Masood., A. Nadeem., F. Masood., F. Hussain., S. A. Khan., A. Wajid, and M. E. Babar (2017). Characteristic features of ifn- $\alpha$ gene in beetal goat breed of punjab, Pakistan, The J. Anim. Plant Sci. 27(1): 345-348

Zedda, M., P. Manca., V. Chisu., S. Gadu., G., Lepore., A. Genovese, and V. Farina (2006). Ancient pompeian dogs: morphological and morphometric evidence for different canine populations. Anat. Histol. Embryol. 35: 319324.

Zide, B. and R. Swift (1998). How to block and tackle the face. Plast Reconstr Surg. 101(3): 840-851. 